\author{
Siddiqua Aamir ${ }^{1 \star}$, Nosheen Latif ${ }^{2}$ and \\ Anila Basit ${ }^{3}$ \\ ${ }^{1}$ Core Department, Prince Mohammad Bin Fahd \\ University, Al Khobar, Kingdom of Saudi Arabia \\ ${ }^{2}$ Department of Clinical Psychology, Frontier Women \\ University, Peshawar, Pakistan \\ ${ }^{3}$ Pulmonology Unit, PGMI Govt. Lady Reading \\ Hospital, Peshawar, Pakistan
}

Dates: Received: 10 September, 2015; Accepted: 09 August, 2016; Published: 11 August, 2016

*Corresponding author: Siddiqua Aamir, Assistant Professor, Associate Chair, Core Department, Prince Mohammad Bin Fahd

University, Al Khobar, Kingdom of Saudi Arabia

E-mail: siddiquanawab21@hotmail.com

ISSN: 2581-3684

www.peertechz.com

Keywords: Counseling; Tuberculosis; Directly observed treatment (DOTS)

\section{Research Article \\ Role of Counselling to Facilitate Compliance to the Dots for the Treatment of Tuberculosis}

\begin{abstract}
Objectives: The objective of the research was to determine and compare the effectiveness of structured counseling to improve adherence and continuation of directly observed treatment (DOTS). As multi drug resistance (MDR) is common due to default among TB patients, to overcome that counseling can play an important role.

Methods: It was a comparative study. Research was conducted at the Pulmonology Unit of PGMI Govt. Lady Reading Hospital Peshawar on both in and out patients from January 2007 to May 2007. The sample comprised of sixty patients $(\mathrm{N}=60)$ diagnosed with pulmonary tuberculosis. The random sampling technique was used for the assignment of the patients to the experimental group $(n=30)$ and a control group $(n=30)$. Data was analyzed with SPSS version 12

Results: The results indicated that the majority of the experimental group patients adhered to the therapy $25(83.3 \%)$ till the last follow -up counseling session dropout rate was $5(16.6 \%)$ while among control group $9(30 \%)$ continued the treatment and kept on coming up for follow up sessions their dropout rate was $21(70 \%)$.

Conclusion: Counseling of patients is important to optimize therapy, aid compliance and to inform patients' of any potential complications of therapy.
\end{abstract}

\section{Introduction}

Pakistan is graded as the sixth worst country in the world affected by TB; there are annually 247,000 newly infected TB patients [1]. Causes for an increase in the number of TB cases are delayed in the diagnosis, poor quality of laboratory services, poor compliance, and inappropriate clinical care. Plentiful studies show that despite the availability of inexpensive and effective therapy, tuberculosis is a leading cause of death, killing 3 million people every year [2]. It is no longer restricted to developing countries, with 400,000 new cases coming into view in industrialized countries each year, and more than 6,000 cases reported a year in the UK [3]. According to the reports non adherence to therapy by patients has been cited as the principal obstacle in eliminating tuberculosis. Lack of educational programs and quality of communication between patients and health workers has been shown to be associated with non-compliance [4].

According to one such study conducted on compliance reported that unintentional non-compliance could result from poor doctor or nurse patient communication or a lack of ability to follow advice. They suggested that better communication and improved health education can improve adherence to therapy [5]. Studies showed that the total health status of patients improved significantly after receiving intensive health education and medication and there was also increased in treatment completion [6,7].

Directly Observed Therapy (DOTS) as a means of improving patient's adherence to anti tuberculosis treatment is very effective. In Africa experience with DOTS has been variable. Treatment completion rates vary from $37 \%$ in the Central African Republic to
$78 \%$ in Kenya and Tanzania. These rates are inadequate to effectively control the disease [8]. Few comparative studies indicate that the effect of intensive health education at start and revisits on patient compliance and outcome of treatment with the well implemented directly observed treatment were good which is the current "Gold Standard" for ensuring high adherence to treatment $[9,10]$.

Russia has one of the highest incidence rates of TB worldwide. Russian Red Cross activities in 2005 continued program implementation with a focus on development of TB education among patients, and their careers through the provision of professional psychological counseling and support for ensuring treatment compliance of TB patients (in line with DOTS) [11].

Other studies in the field of TB have also revealed and identified important areas like Information, Education, and Communication (IEC) for the improvement of control programs [12].

The role of health communication in achieving global TB control goals in Peru paid special attention to training health care workers in interpersonal communication and counseling skills. With an effective communication strategy Peru and Vietnam reached their goals of detecting 70 percent TB cases and successfully treating 85 percent of them [13].

A Qualitative study conducted in Iran found out that despite effective diagnosis and treatment, the prevalence of tuberculosis (TB) is still growing. The directly observed treatment, short-course (DOTS) strategy to treat TB was introduced by the World Health Organization more than a decade ago. Little is known about patients' experience of TB treatment, according to DOTS [14]. 
It can be assumed that patients who receive repeated structured counseling are more likely to continue with DOTS than the patients who receive only routine DOTS therapy. The intent of this research was to determine and compare the effectiveness of counseling to improve adherence and continuation of TB treatment.

\section{Method}

\section{Participants}

It was a comparative study conducted at the Pulmonology Unit of PGMI Govt. Lady Reading Hospital Peshawar on both in and out patients from January 2008 to May 2008.Patients of both sexes suffering from TB by consultant Pulmonologist and who were willing to participate in the study were included. Those patients who were unwilling and unable to communicate and were confused and drowsy were excluded. Patients below 16 years and above 60 years and living in Afghanistan were also not included in the present research.

The sample comprised of sixty patients $(\mathrm{N}=60)$ all newly diagnosed with TB. The random sampling technique lottery method was used for the assignment of the patients to the experimental group $(n=30)$ and control group $(n=30)$. Each member of the population was assigned a unique number. Each number was placed in a bowl and mixed thoroughly. The blindfolded researcher then picked numbered tags from the bowl. All the individuals bearing the numbers picked by the researcher were the participants for the study.

\section{Procedure}

The Demographic profile of both groups was obtained and routine DOTS therapy was given to all the patients of both experimental and control groups ( $\mathrm{N}=60)$. At the initial assessment (first session) to each patient counselor individually explained that their main aim was to achieve adherence to the treatment by making the patients understand that DOTS was the readily available and most convenient treatment for TB. They could only accomplish that stated goal of continuation, adherence and complete recovery through collaboration with the counselor by attending all weekly follow up sessions of counseling and collecting medication. Many obstacles were anticipated by the patients because of their misconceptions about the DOTS. Those obstacles were addressed by giving a detailed account of DOTS to patients and their relatives, especially that drugs would be free of cost, dosage for one week would be provided, expected side effects of the drugs were explained by the pulmonologists, there would be regular follow up counseling sessions for 6 months and in added incentive of Rs. 50 per session would be given to patients. The team of counselors was in constant touch via telephone with an experimental group to monitor progress and give reminder for weekly sessions. Later counseling sessions were focused on developing positive helping relationships with patients. Counselors made it sure to connect with them in order to make them feel that they genuinely care about their well-being and understand what they are going through. To develop solid relationships with patients, a safe environment was created where patients felt comfortable enough to open up and talk to the counselor about anything that was on their minds. Counselors helped patients to realize that despite their circumstances they had positive strengths. For counseling sessions to be more effective counselors also worked on patients who were not getting actively engaged and were resistant, steps like further motivation to encourage continuation of treatment during every follow up session to reduce resistance were taken. Counselors during every session continued working on the biases of the patients regarding treatment and how that could impact the course of continuation. Counselors also provided a brief verbal assessment report at the start and end of every session to give patients an opportunity to see how his/her behavior or attitude towards treatment might contribute to an undesirable or unhealthy situation like discontinuation of treatment. Furthermore, counseling sessions were designed to prevent, intervene, or address avoidance behaviors and practices, behavior modification towards intervention, adherence to the medication, pacing social activities and involvement of primary caregiver(s) in supervising and administration of medication of patients, was done with the experimental group $(n=30)$ only for four sessions (one per week 45 minutes duration in addition to routine DOTS therapy [15]. Control group $(n=30)$ was kept blind to counseling sessions.

Adherence to the treatment of $\mathrm{TB}$ was assessed by making one primary attendant in charge of drug administration to the patient, so making certain that the drugs were taken regularly. The counselor would make that certain on every session that patient is accompanied by the same caregiver and empty blisters of tablets were brought back to the outpatient department.

To further define the usefulness of counseling in the treatment of TB patients of both groups was provided with medication for one week only.

The effectiveness of the counseling was also measured by comparing dropout rate per week in experimental and control groups.

The data obtained was analyzed with SPSS version 12 .

\section{Results}

The experimental group mean age was $29.8 \pm 2.4$ while control group mean age was $28.6 \pm 2.3$. Among experimental group $9(30 \%)$ were females and $21(70 \%)$ were males, whereas among control group 11(36.6\%) were females and 19(63.3\%) were males. Amongst experimental group 13(43.3\%) were married, while among control group $15(50 \%)$ subjects were married. Seventeen (56.6\%) patients from experimental group whilst 15 (50\%) from the control group were unmarried. The majority of the patients from both groups was educated up to secondary level $26(86.6 \%)$ from the experimental group an (20(66.6\%) among the control group, 23 (76.6\%) from the experimental group while 20(66.6\%) amid control group were from rural background. Twenty (66.6\%) from the experimental group and $24(80 \%)$ among control group were from low socioeconomic class.

Mean follow up sessions for the experimental group were $3.7 \pm$ 0.6 and for the control group was $1.9 \pm 2.1, t$ (58) 4.5141, $p<0.0001$ statistically significant difference was found between two groups.

The results at the end of four weeks last follow up counseling session showed that the majority of the experimental group patients continued and adhered to the DOTS and counseling sessions 25 (83.3\%) with the dropout rate of $5(16.6 \%)$ till the last follow up 
counseling session while among control group $9(30 \%)$ patients with a dropout rate of $21(70 \%)$ continued the DOTS and kept on coming up for follow up sessions. The odds ratio was $11.66795 \%$ confidence interval from 3.3841 to 40.2207 (Table 1).

\section{Discussion}

At the end of the research last fourth follow up the session noteworthy difference in the dropout rate of experimental and control group was observed, from that the usefulness and effectiveness of the counseling in improving the adherence to the TB treatment could be determined. The objective of the present study was to facilitate patients to achieve the goal of continuation and adherence to the DOTS after comprehending the facts regarding treatment regime through structured counseling sessions focused on changing patient's attitude and behavior towards TB treatment.

In the current research mainstream of patients from both groups were from rural background $43(71.6 \%)$ with low socioeconomic status $50(83.3 \%)$ less years of education with 6.1 mean. Some studies suggested that psycho-social elements had been largely ignored under DOTS. The results of one such study conducted in two DOTS centers in India suggested that $\mathrm{TB}$ patients had certainly typical illness behavior profile. They suggested that for a disease like TB that has so many psycho-social parameters, a valid illness profile of the patients would also be studied [16].

According to a study conducted on the TB patients attending private health care service showed that intensive counseling and modified methods of supervision were successful in achieving cure rates as good as DOTS. Along with adherence to treatment, the cure rate was $87.7 \%$, with no relapse in 6 months follow up and $80 \%$ patients resumed normal life [17]

Studies conducted in India have revealed that lack of practical information about treatment for TB was common. More than half of the households surveyed knew that primary health centers existed, but only $15 \%$ knew that free TB treatment was available there [18] A household survey conducted in North West Frontier Province of Pakistan regarding knowledge, attitude and practice among local communities about the management of $\mathrm{TB}$ also revealed that a significant number of respondents had substantial knowledge of TB but did not know that medicines are available free of cost at government health facilities [19].

A Qualitative Study conducted in Iran on Patients' Experience of Tuberculosis Treatment Using Directly Observed Treatment, Short-

\begin{tabular}{|l|l|l|l|l|}
\hline \multicolumn{5}{|l|}{ Table 1: shows weekly dropout rate of experimental and control groups' patients. } \\
\hline S.no & $\begin{array}{l}\text { Experimental } \\
\text { Group (n=30) }\end{array}$ & $\begin{array}{l}\text { Dropout } \\
\text { Rate }\end{array}$ & $\begin{array}{l}\text { Control Group } \\
(\mathbf{n = 3 0})\end{array}$ & $\begin{array}{l}\text { Dropout } \\
\text { Rate }\end{array}$ \\
\hline $\begin{array}{l}\text { Follow-up } \\
\text { (week 1) }\end{array}$ & $30-0=30$ & 0 & $30-6=24(80 \%)$ & $6(20 \%)$ \\
\hline $\begin{array}{l}\text { Follow-up } \\
\text { (week 2) }\end{array}$ & $30-1=29(96.6 \%)$ & $1(3 \%)$ & $\begin{array}{l}24-10=14 \\
(46.6 \%)\end{array}$ & $10(33.3 \%)$ \\
\hline $\begin{array}{l}\text { Follow-up } \\
\text { (week 3) }\end{array}$ & $29-2=27(90 \%)$ & $2(6.6 \%)$ & $14-3=11(36.6 \%)$ & $3(10 \%)$ \\
\hline $\begin{array}{l}\text { Follow-up } \\
\text { (week 4) }\end{array}$ & $27-2=25(83.3 \%)$ & $2(6.6 \%)$ & $11-2=9(30 \%)$ & $2(6.6 \%)$ \\
\hline Total & $25(83.3 \%)$ & $5(16.6 \%)$ & $9(30 \%)$ & $21(70 \%)$ \\
\hline
\end{tabular}

Course (DOTS) concluded successful completion of TB treatment requires an effective partnership between the patient and health care professionals, and a harmony between the cultural context, the attitude of the patient, family support and health literacy. Future health policies should address these issues to improve patients' adherence to DOTS [14].

\section{Conclusion}

It is concluded from the findings of current research that counseling can play very major role in improving continuation and adherence in TB patients. In fact, in routine management of TB no systematic advice and counseling is provided to the patient that results in inappropriate management of compliance in tuberculosis patients with DOTS. Public health education can only contribute to the accomplishment of control programs, when family members and peers are involved. Further high quality researches using focused counseling techniques for TB patients should be a priority, since adherence and continuation are fundamentally important to the successful use of DOTS.

\section{References}

1. Youssef A (2005) Unpublished report: Assessment of Aurat Foundation.

2. Grange JM, Zumla A (1999) A paradox of the global emergency of tuberculosis. Lancet 353-996.

3. Caunce A (2006) Dot Pharmacy In the shadow of TB. Miller Freeman plc.

4. Moulding TS (1999) Medication monitors to treat tuberculosis, a supplement to directly observed therapy. Am J Respir Crit Care Med 159: 989-991.

5. Cochrane GM, Horne R, Chanez P (1999) Compliance in Asthma. Respir Med 93: 763-769.

6. Chadha SL, Bhagi RP (2000) Treatment outcome in TB patients placed under directly observed treatment short course (DOTS): a cohort study. Ind J Tub 47: 155.

7. D'Souza J (2003) Effect of intensive health education on adherence to treatment in sputum positive pulmonary tuberculosis patients. Ind J Tub 50 : 33-38.

8. (2001) Tuberculosis control -how can we do better? Publications, press release. Medical research council of South Africa.

9. Bhatt S, Mukherjee S, Myneedu VP, Jain RC, Sarin R (1998) Unsupervised intermittent short course chemotherapy with intensive health education. Ind $\mathrm{J}$ Tub 45: 145.

10. Prasad R, Rizavi DM, Kant S, Jani A (2001) A comparison of unsupervised treatment with intensive health education and directly observed treatment in tuberculosis. Ind J Tub 48: 21

11. WHO (2015) country profile: Russian Federation.

12. Kumar P (2005) Journey of tuberculosis control movement in India: national tuberculosis program to revised national tuberculosis control program. Ind $J$ Tub 52: 63-71.

13. Thuy DO, Llanos-Zavzlga F, Huong NTM, Tawfik Y, Church-Balin C (2004) The role of health communication in achieving global TB control goals-lessons from Peru, Vietnam and beyond. Health communication insights summary. Baltimore: Health communication partnership based at the Johns Hopkins Bloomberg School of public health/Center for communication programs.

14. Behzadifar M, Mirzaei M, Behzadifar M, Keshavarzi A, Behzadifar M, et al. (2015) Patients' Experience of Tuberculosis Treatment Using Directly Observed Treatment, Short-Course (DOTS): A Qualitative Study. Iran Red Crescent Med J 17: e20277. 
15. (2002) An expanded DOTS framework for effective tuberculosis control Geneva, World Health Organization.

16. Bhasin SK, Mittal A, Aggarwal OP, Chadha RK (2001) Illness behavior of tuberculosis patients undergoing DOTS therapy: a case-control study. Ind J Tub 48: 81.

17. Joseph MR, POrath S, Eapen CK (2000) Integrating private health care in the national tuberculosis program. Experience from Ernakulam-Kerala. Ind J Tub 17-19.
18. Pathania V, Almeida J, Kochi A (1997) TB patients' private for profit health care provider for India. Geneva, World Health Organization. The global program.

19. (2001) Knowledge, attitude, and practices among local communities regarding management of tuberculosis: a household survey NWFP in Pakistan (Unpublished report) BY German association of development consultant (AGEG) for its GTZ funded project 'Strengthening the tuberculosis control program in NWFP/FATA, Pakistan by Department of community health sciences, Agha Khan University, Karachi, Pakistan. 